\title{
ASSOCIATION OF LOSS OF HETEROZYGOSITY WITH SHORTER SURVIVAL IN PRIMARY GLIOBLASTOMA PATIENTS
}

\author{
Dorota Jesionek-Kupnicka ${ }^{1}$, Mazgorzata Szybka², Piotr Potemski ${ }^{3}$, \\ Dominika KulcZycKa-Wojdala ${ }^{4}$, DARiusz Jaskólski ${ }^{5}$, Michą BieńkOwski², \\ WiesŁaw SKowroński ${ }^{6}$, WielisŁaw PapierZ ${ }^{7}$, RAdZisław KORdeK ${ }^{1}$, IZABela Zawlik ${ }^{8}$
}

\author{
${ }^{1}$ Department of Pathology, Chair of Oncology, Medical University of Lodz, Poland \\ 2Department of Molecular Pathology and Neuropathology, Chair of Oncology, Medical University of Lodz, Poland \\ ${ }^{3}$ Department of Chemotherapy, Chair of Oncology, Medical University of Lodz, Copernicus Memorial Hospital, \\ Poland \\ ${ }^{4}$ Central Laboratory of Medical University of Lodz (CoreLab), Poland \\ ${ }^{5}$ Department of Neurosurgery, Medical University of Lodz, Norbert Barlicki Teaching Hospital, Poland \\ ${ }^{6}$ Department of Neurosurgery, Perzyna Memorial Specialist Hospital, Kalisz, Poland \\ ${ }^{7}$ Chair and Department of Pathomorphology, Medical University of Lodz, Poland \\ ${ }^{8}$ Department of Medical Genetics, Institute of Nursing and Health Sciences, Medical Department, \\ University of Rzeszow, Poland
}

\begin{abstract}
Loss of heterozygosity (LOH) co-deletion 1p/19q, MGMT promoter methylation and/or IDH1 mutation generally signify a better prognosis for patients with glioma. However, the influence of $1 \mathrm{p} / 19 \mathrm{q}$ co-deletion and the LOH on other chromosomes in primary glioblastoma on survival is still debatable. The aim of our study was to identify LOH on chromosomes 1p, 19q, 9p, 10q, 13q, and 17p, and evaluate their impact either alone or $1 \mathrm{p} / 19 \mathrm{q}$ co-deletion or by groups of $\mathrm{LOH}$ on the overall survival of 42 primary glioblastoma patients without an oligodendroglial component. These patients were additionally molecularly characterized for EGFR amplification, IDH1 mutations and TP53 mutations. We assessed their influence on the overall survival of glioblastoma patients. $\mathrm{LOH}$ in at least one of the loci on all examined chromosomes was detected in $65 \%$ of cases and was significantly associated with shorter overall survival (hazard ratio 3.07; 95\% CI: 1.29-7.31, p = 0.006). 1p/19q co-deletion was infrequent $(7.14 \%)$ and had no impact on overall survival. Our results indicate that in primary glioblastoma a specific LOH group analysis may be important for the prognosis. LOH 1p/19q co-deletion is rare in glioblastoma without an oligodendroglial component and has no impact on patient survival.
\end{abstract}

Key words: glioblastoma, LOH 1p, 19q, 9p, 10q, 13q and 17p, survival.

\section{Introduction}

Glioblastoma (GB) carries complex genetic alterations resulting in a different molecular and epidemiological profile. In primary glioblastoma, the most common molecular alterations are LOH 10q (over 70\%), EGFR amplification (about 40\%), MDM2 amplification, LOH $10 \mathrm{p}$ and $10 \mathrm{q}, p 16^{I N K} 4 a$ and PTEN mutation. In secondary glioblastoma, the first common molecular event in multistep carcinogenesis is the mutation of IDH1, TP53, and LOH on 17p, 10q and 19q [1-3].

There are three molecular markers related to better outcome of gliomas: MGMT promoter methylation is associated with a stronger benefit of radiochemotherapy in glioblastomas; IDH1 mutations are a strong and independent predictor of survival in both low-grade and high-grade gliomas; while 1p/19q co-deletion strongly predicts prolonged response to treatment and longer 
survival in oligodendroglial tumors [3-6]. However, recent data showed that the prognostic significance of these markers should be used with caution [7].

MGMT promoter methylation has been associated with better survival in glioblastoma treated with radiotherapy and alkylating agents [6]. In our previous study, $M G M T$ promoter methylation had no prognostic value in glioblastoma patients who were treated only with surgery and radiotherapy [8]. With regards to MGMT methylation status and the occurrence of EGFR amplification, the group of glioblastoma that shows no hypermethylation with amplification constituted about $19 \%$ of cases and the same percentage was a group with hypermethylation and amplification. These patients could potentially benefit from bimodal chemotherapy with an alkylating agent and/or EGFR blocker additionaly [9].

Mutations of the IDH1/IDH2 gene inversely correlated with glioma grade [3, 10]. IDH1/IDH2 mutations occurred mainly in secondary glioblastomas $(>70 \%)$, associated with young age of patients and with an increase in overall survival, but were very rare in primary glioblastomas $(<5 \%)$ [3]. IDH2 mutations are less frequent and prevail in anaplastic oligodendrogliomas (5\%) and oligoastrocytomas (6\%) [3]. $100 \%$ of patients with 1p/19q co-deletion had IDH1/IDH2 gene mutations and indicated occurrence of an oligodendroglial component in glioblastoma [11].

$\mathrm{LOH} 1 \mathrm{p}$ was detected in up to $24 \%$ of glioblastomas [12-14] and the frequency of $\mathrm{LOH} 1 \mathrm{p}$ is similar in primary and secondary glioblastoma $(12 \%$ and $15 \%$, respectively) [15], but its prognostic significance is not well established. It has been suggested that the isolated deletion of $1 \mathrm{p}$ may be associated with longer survival in high-grade gliomas composed of either pure astrocytic or mixed astrocytic-oligodendroglial phenotypes [16]. In one study, LOH 1p was found to be associated with longer survival in glioblastoma patients [17]; however, another study reported no influence of isolated LOH 1p on survival [18]. LOH 19q (a common deletion at $19 q 13.3)$ frequency varies from $5 \%$ to $33 \%$ $[12,14,18]$ and it is more frequent in secondary glioblastoma (54\%) than in primary glioblastoma (6\%) [15]. However, its impact on the prognosis in GB is not clear and remains controversial $[14,17,19,20]$. Although the co-deletion LOH 1p/19q is an important predictive marker of chemosensitivity in oligodendrogliomas [5], its occurrence is not frequent in primary GB $[14,18,21]$. The clinical significance of $1 \mathrm{p} / 19 \mathrm{q}$ in glioblastoma is reported by some $[4,18]$ but another study showed no impact on the prognosis of GB [21].

It was reported that $\mathrm{LOH} 10 \mathrm{q}$ is associated with shorter survival and poor clinical outcome $[1,2]$, whereas other studies have found no such association [18, 22]. The frequency of $\mathrm{LOH}$ on chromosome 10 in primary and secondary GB is similar ( $47 \%$ in primary vs. $54 \%$ in secondary GB) but the differences concern the pat- tern of chromosomal loss [23]. The loss of an entire copy of chromosome 10 was usually observed in primary glioblastoma, while $\mathrm{LOH}$ is restricted to $10 \mathrm{q}$ in secondary glioblastoma $[1,23]$.

Despite intensive investigations the molecular prognostic factors for primary glioblastoma are still debatable. The aim of our study was to evaluate the impact of LOH on chromosomes 1p, 19q, 9p, 10q, 13q, $17 \mathrm{p}$ either alone or by groups of LOH and TP53 mutations, and EGFR amplification on the survival of primary glioblastoma patients. We also focused on the occurrence and clinical significance of LOH 1p/19q in GB without an oligodendroglial component.

\section{Material and methods}

\section{Tumor samples and DNA extractions}

The material consisted of tumor tissue with primary GB and paired peripheral blood from 42 patients (agreement of Bioethical Committee of Medical University of Lodz, Poland RNN/192/03/KE). Tumor samples were obtained from 42 patients with primary glioblastoma (21 males and 21 females) who were treated in the Departments of Neurosurgery of "Copernicus" Memory Hospital in Lodz, Barlicki Clinical Hospital of Medical University of Lodz, Regional Specialist Hospital in Olsztyn, and Perzyna Memorial Hospital in Kalisz, Poland, from 2002 to 2005. Informed consent from patients was obtained in every case.

The mean age of the patients was $59.1 \pm 11.8$. All tumors were histopathologically examined and classified according to the World Health Organization (WHO) classification of tumors of the CNS [24].

Patients with primary glioblastoma were selected on the basis of a short clinical history and the presence of histopathological features of glioblastoma without evidence of precursor low-grade astrocytomas at the first biopsy [25]. No oligodendroglial components were found in the histopathological study. According to the classical model of the molecular GB pathway, primary glioblastoma is characterized by high incidence of EGFR amplification (about 40\%) and low frequency of IDH1 mutations $(<5 \%)$; additionally, TP53 mutations are less frequent in primary GB $[26,27]$. To ascertain that the tumors studied were primary glioblastomas we used the following molecular criteria: frequencies of $E G F R$ amplification (37.5\%), IDH1 mutation (2.4\%), and TP53 mutation (26.2\%); the results were partly published before (EGFR amplification and TP53 mutations) [8]. Moreover, the $1 \mathrm{p} / 19 \mathrm{q}$ co-deletion was infrequent ( 3 cases), and in 2 of these cases there was no co-presentation with IDH1 mutation (one of these cases was not determined for IDH1 mutation), which is typical for primary glioblastoma without an oligodendroglial component [11] (Table I). It means that these cases showed molecular markers typical for primary GB. 
Table I. Clinical data and results of molecular alterations analysis

\section{No. Age/sex OS LOH10p LOH9p LOH17p LOH13q LOH1p LOH19q (MS)}

EGFR AMPL

TP53 MUTATION EXON (E), CODON, AND EFFECT

\begin{tabular}{|c|c|c|c|c|c|c|c|c|c|c|c|}
\hline 1. & $69 / \mathrm{M}$ & 3 & yes & yes & yes & NI & no & no & yes & $\begin{array}{c}\text { E 8, 273, } \\
\text { CGT }>\text { CAT, Arg-His }\end{array}$ & no \\
\hline 2. & $57 / \mathrm{M}$ & 11 & yes & no & yes & no & no & yes & yes & $\begin{array}{c}\text { E } 8,282, \\
\text { CGG }>\text { TGG, Arg-Trp }\end{array}$ & no \\
\hline 3. & $67 / F$ & 2 & no & no & no & yes & no & yes & no & $\begin{array}{c}\text { E } 5,175, \\
\text { CGC>CAC, Arg-His } \\
\text { E 8, 282, } \\
\text { CGG }>\text { TGG, Arg-Trp }\end{array}$ & no \\
\hline 4. & $76 / \mathrm{F}$ & 5 & yes & yes & NI & no & yes & no & yes & no & no \\
\hline 5. & $43 / \mathrm{F}$ & 12 & no & yes & no & no & no & no & no & $\begin{array}{c}\text { E } 5,173, \\
\text { GTG }>\text { TTG, Val-Leu }\end{array}$ & no \\
\hline 6. & $70 / \mathrm{F}$ & 11 & no & no & no & no & no & no & no & $\begin{array}{c}\text { E } 5,179, \\
\text { CAT }>\text { GAT, His-Asp }\end{array}$ & no \\
\hline 7. & $62 / \mathrm{F}$ & 20 & no & no & no & no & no & no & no & no & no \\
\hline 8. & $72 / \mathrm{F}$ & 5 & no & no & no & no & yes & yes & no & no & ND \\
\hline 9. & 64/M & 14 & yes & $\mathrm{NI}$ & $\mathrm{NI}$ & $\mathrm{NI}$ & no & yes & yes & no & no \\
\hline 10. & $71 / \mathrm{F}$ & 19 & yes & yes & no & no & yes & no & yes & no & no \\
\hline 11. & $54 / \mathrm{M}$ & 12 & yes & no & no & no & yes & no & yes & no & no \\
\hline 12. & $68 / \mathrm{F}$ & 9 & no & no & no & no & no & yes & no & no & no \\
\hline 13. & $66 / \mathrm{F}$ & 2 & no & $\mathrm{NI}$ & $\mathrm{NI}$ & no & $\mathrm{NI}$ & yes & yes & no & no \\
\hline 14. & $51 / \mathrm{M}$ & 10 & no & $\mathrm{NI}$ & $\mathrm{NI}$ & no & no & no & yes & no & no \\
\hline 15. & $60 / \mathrm{F}$ & 9 & NI & yes & NI & no & no & NI & yes & no & no \\
\hline 16. & $69 / \mathrm{F}$ & 11 & no & yes & no & no & no & no & no & no & no \\
\hline 17. & $50 / \mathrm{M}$ & 15 & yes & no & no & no & no & yes & no & no & no \\
\hline 18. & $69 / \mathrm{F}$ & 12 & yes & $\mathrm{NI}$ & no & no & no & no & yes & no & no \\
\hline 19. & $67 / \mathrm{M}$ & 13 & yes & no & yes & yes & no & no & no & $\begin{array}{c}\text { E 6, 190, } \\
\text { CCT }>\text { TCT, Prol-Ser }\end{array}$ & no \\
\hline 20. & $52 / \mathrm{F}$ & 3 & no & no & no & no & no & yes & no & no & no \\
\hline 21. & $65 / F$ & 7 & no & no & no & no & no & no & no & no & no \\
\hline 22. & $74 / \mathrm{M}$ & 8 & no & no & no & no & no & no & no & no & no \\
\hline 23. & $34 / \mathrm{M}$ & 28 & no & no & no & no & no & no & no & $\begin{array}{c}\text { E 8, 273, } \\
\text { CGT > TGT, Arg-Cys }\end{array}$ & no \\
\hline 24. & $40 / \mathrm{M}$ & 26 & no & no & no & no & no & no & no & no & no \\
\hline 25. & $75 / \mathrm{F}$ & 48 & no & no & no & no & no & no & no & $\begin{array}{c}\text { E 7, 234, } \\
\text { TAC> CAC, Trp-His }\end{array}$ & yes \\
\hline 26. & $44 / \mathrm{M}$ & 20 & no & no & no & yes & no & no & no & no & no \\
\hline 27. & $60 / \mathrm{M}$ & 3 & yes & no & no & no & no & no & yes & no & no \\
\hline 28. & 64/M & 14 & ND & ND & $\mathrm{ND}$ & ND & ND & ND & ND & no & no \\
\hline 29. & $62 / \mathrm{M}$ & 12 & no & no & no & no & no & no & yes & no & no \\
\hline 30. & $66 / \mathrm{M}$ & 26 & ND & ND & ND & ND & ND & ND & ND & no & no \\
\hline 31. & $55 / F$ & 22 & no & no & no & no & no & no & no & no & no \\
\hline 32. & $51 / \mathrm{M}$ & 8 & no & no & no & no & no & no & no & $\begin{array}{c}\text { E 7, 237, } \\
\text { ATG }>\text { ATA Met-Ile }\end{array}$ & no \\
\hline 33. & $75 / \mathrm{F}$ & 11 & no & no & yes & no & no & no & no & $\begin{array}{c}\text { E } 8,267, \\
\text { CGG }>\text { TGG, Arg-Trp }\end{array}$ & no \\
\hline 34. & $68 / \mathrm{F}$ & 5 & yes & yes & no & no & yes & no & no & no & no \\
\hline 35. & $47 / \mathrm{F}$ & 17 & yes & no & no & no & yes & yes & yes & no & no \\
\hline 36. & $50 / \mathrm{F}$ & 11 & yes & no & no & no & no & no & no & no & no \\
\hline
\end{tabular}


Table I. Cont.

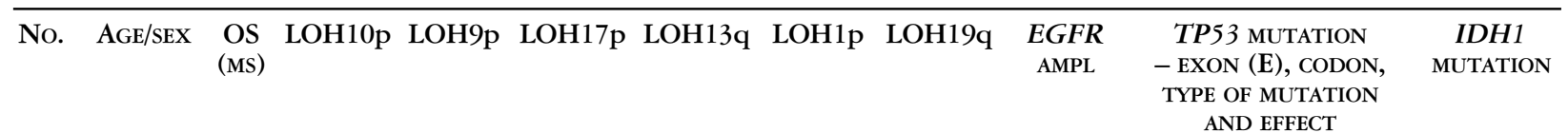

\begin{tabular}{|c|c|c|c|c|c|c|c|c|c|c|c|}
\hline 37. & $23 / \mathrm{M}$ & 6 & no & no & no & no & no & no & no & no & no \\
\hline 38. & $52 / \mathrm{M}$ & 16 & no & yes & no & no & no & no & yes & no & no \\
\hline 39. & $58 / \mathrm{F}$ & 18 & no & no & yes & no & no & no & no & $\begin{array}{c}\text { E } 6,215, \\
\text { AGT }>\text { AAT, Ser-Asn }\end{array}$ & no \\
\hline 40. & $52 / \mathrm{M}$ & 11 & yes & no & no & no & no & no & no & no & no \\
\hline 41. & $51 / \mathrm{M}$ & 12 & no & no & no & yes & yes & yes & yes & no & no \\
\hline 42. & $59 / \mathrm{M}$ & 13 & no & no & no & no & no & no & no & no & no \\
\hline
\end{tabular}

All patients underwent total or partial surgery and radiotherapy and 7 underwent chemotherapy (temozolomide). The patients who received chemotherapy were not treated routinely with temozolomide according to the previous standard protocol therapy in the years 2002-2005 in Poland.

DNA was isolated by standard proteinase $\mathrm{K}$ digestion and phenol/chloroform extraction from frozen tumor tissue samples taken before radio- and/or chemotherapy, and from paired samples of peripheral blood leukocytes (WBC). Histological assessment of tissue fragments chosen for this study confirmed that all specimens consisted of at least $80 \%$ tumor cells.

\section{Loss of heterozygosity analysis}

Loss of heterozygosity analysis was performed using paired tumor specimens and corresponding peripheral blood samples. The $\mathrm{LOH}$ on chromosomes $1 \mathrm{p}$, 9p, 10q, 13q, 17p, and 19q were examined using PCR with the markers D1S508 (approximate chromosomal localization 1p36.23), D9S156 (9p22), D9S162 (9p219p22), D10S587 (10q25-10q26), D10S536 (10q23), D13S256 (13q21-13q14), D17S675 (17p13.2) D19S206 (19q13.3), and D19S219 (19q13.3). Forward primers were fluorescence-labeled at the 5' end. The PCR was performed in thermocycling conditions established individually for each pair of primers. The PCR products were denatured and separated by gel electrophoresis in a LiCor automatic sequencer system for the analysis of PCR-generated alleles.

\section{TP53 sequencing analysis}

Four genomic regions of the TP53 gene (exons 5-8) were amplified by PCR, as described previously [8]. Sequence analysis was performed by the dideoxy termination method using the SequiTherm Excel DNA Sequencing Kit (Epicentre Technologies, Madison, WI) and commercially available fluorescent-labeled primers as described previously [8]. Products of the se- quencing reaction were visualized and analyzed using a LiCor automated laser fluorescence sequencer.

\section{IDH1 sequencing analysis}

Exon 4, including codon 132 of the IDH1 gene, was amplified by PCR and sequenced using the dideoxy termination method and SequiTherm Excel DNA Sequencing Kit (Epicentre Technologies). The commercially available primers used for PCR amplification of the DNA sequences were: IDH1 - 5'-GGCACCCATCTTCTGTGTTT-3' (sense) and 5'-ATATATGCATTTCTCAATTTCA-3' (antisense). The sequencing primers used were: IDH1 exon 4-5'-CGGTCTTCAGAGAAGCCATT-3' (sense) and IDH1 exon 4 - 5'-CACATTATTGCCAACATGAC-3' (antisense). A Li-Cor automatic sequencer system was applied for the separation and analysis of PCR sequencing products.

\section{EGFR amplification analysis}

Multiplex PCR was performed for evaluation of EGFR amplification with superoxide dismutase 1 (SOD1) used as a reference gene as described previously [28].

\section{Statistical analysis}

The Kaplan-Meier method was used to estimate overall survival, defined as the time from the date of the first surgery to the last observation. Differences in survival distributions were evaluated using a log-rank test. Univariate and multivariate survival analyses were performed using the Cox proportional hazard regression model. All results were considered statistically significant when two-sided p was $<0.05$.

\section{Results}

\section{Loss of heterozygosity}

Loss of heterozygosity in at least one of the loci on all examined chromosomes was detected in $65 \%$ (26/40) of the informative cases. The results of $\mathrm{LOH}$ 
Table II. Frequency of LOH on examined chromosomes

\begin{tabular}{lcccccccc}
\hline & LOH & LOH & LOH & LOH & LOH & LOH & LOH & TOTAL \\
& $1 \mathrm{p}$ & $19 \mathrm{q}$ & $9 \mathrm{p}$ & $10 \mathrm{q}$ & $13 \mathrm{q}$ & $17 \mathrm{p}$ & $1 \mathrm{p} / 19 \mathrm{q}$ & LOH \\
\hline $\begin{array}{l}\text { Percent of } \\
\text { informative }\end{array}$ & $17.9 \%$ & $25.6 \%$ & $22.6 \%$ & $35.8 \%$ & $10.5 \%$ & $14.3 \%$ & $7.14 \%$ & $65 \%$ \\
cases & $(7 / 39)$ & $(10 / 39)$ & $(8 / 36)$ & $(14 / 39)$ & $(4 / 38)$ & $(5 / 35)$ & $(3 / 35)$ & $(26 / 40)$ \\
\hline
\end{tabular}

A

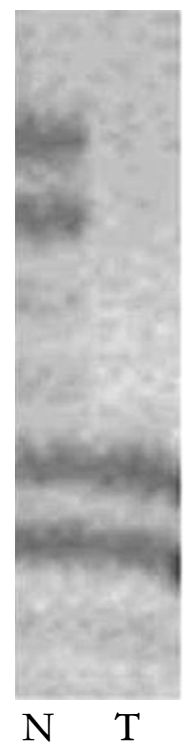

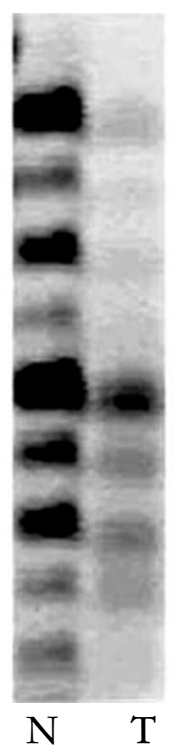

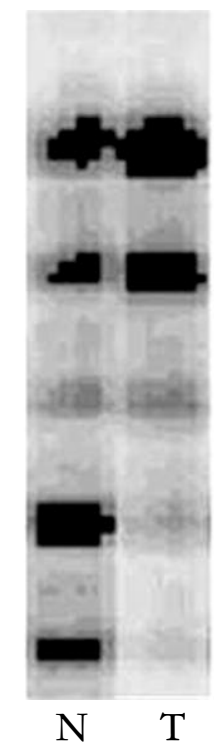

B

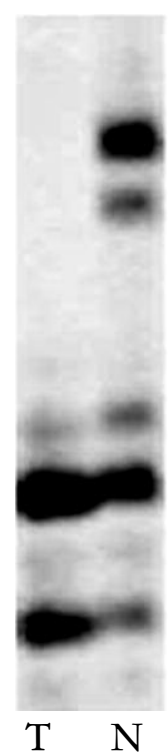

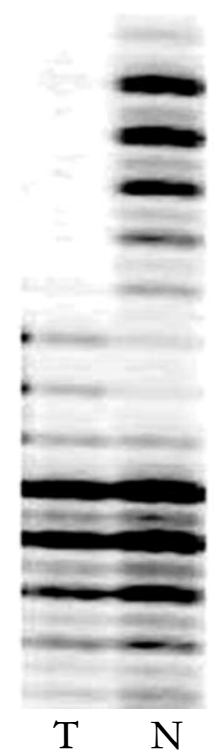

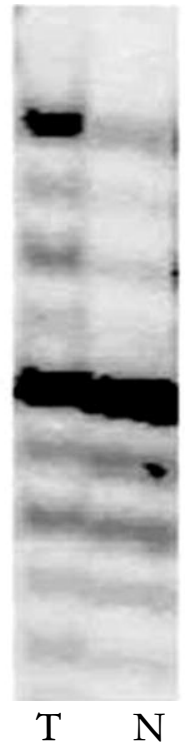

Fig. 1. The representative results of $\mathrm{LOH}$ analysis: A) LOH 1p and B) LOH 19q. T - tumor sample; $\mathrm{N}$ - a corresponding normal tissue (blood)

are shown in Table I and II. Representative results for LOH $1 p$ and $19 q$ analysis are shown in Fig. 1.

\section{Loss of heterozygosity and the influence on prognosis and age}

The mean survival for the whole group of 42 patients was $12.9 \pm 8.5$ months; median was 11.5 months (range 2-48). The correlations between $\mathrm{LOH}$ and survival are shown in Table III.

The clinical outcome of patients with $\mathrm{LOH}$ in at least one of the loci examined on all chromosomes, except LOH 13q (any LOH; $\mathrm{n}=26$ ), was significantly worse than that of patients without $\mathrm{LOH}$ (no LOH; $\mathrm{n}=14)(\log$-rank, $\mathrm{p}=0.007)$ (Fig. 2). LOH 13q was excluded from this calculation because it was associated with a hazard ratio (HR) below 1.00, while all other $\mathrm{LOH}$ were associated with $\mathrm{HR}>1.00$. The median overall survival of the patients with any $\mathrm{LOH}$ was 11 months (range 2-19 months), while median survival time was 13.0 months in the group of patients without LOH (range 6-48 months). Cox univariate analysis confirmed that patients with $\mathrm{LOH}$ at any of the loci examined was related to a significantly increased risk of death (hazard ratio 3.07; 95\% CI: 1.29-7.31; $\mathrm{p}=0.006)$. There was no statistically significant as- sociation between LOH 1p/19q and survival (hazard ratio 1.17 ; 95\% CI: $0.36-3.8 ; \mathrm{p}=0.79$ ). There was no statistically significant association between other $\mathrm{LOH}$, as a single parameter, and overall survival (Table III). The correlation between $\mathrm{LOH}$ (as a single parameter or a group of $\mathrm{LOH}$ ) and age also was not statistically significant.

\section{EGFR, TP53 and IDH1 alterations and} the influence on prognosis and age

$E G F R$ amplification was identified in $37.5 \%$ (15/40). IDH1 mutation was found only in one case $(2.4 \%)$ (case 25$)$. In this case there was no $1 \mathrm{p} / 19 \mathrm{q}$ codeletion. One case was not determined for IDH1 mutation. The TP53 mutations were identified in $26.2 \%$ (11/42) of cases within exons 5, 6, 7 and 8. All the mutations of TP53 were missense and are equally distributed through the exons (Table I). There was no difference in survival between patients with these molecular alterations and patient age.

\section{Discussion}

The clinical outcome of glioblastoma patients with loss of heterozygosity on chromosomes 1p, 19q, 9p, 10q, 
Table III. Correlations between LOH and survival

\begin{tabular}{|c|c|c|}
\hline & Median SURVIVAL TIME & $\begin{array}{l}\text { HAZARD RATIO (HR) } \\
\text { P-VALUE }\end{array}$ \\
\hline LOH $1 p(+)(n=7)$ & 12 months (range 5-19) & \multirow{2}{*}{ HR $1.31 ; 95 \%$ CI: $0.57-3.03 ; \mathrm{p}=0.537$} \\
\hline LOH 1p (-) $(\mathrm{n}=32)$ & 11 months (range 2-48) & \\
\hline LOH 19q $(+)(n=10)$ & 10 months (range 2-17) & \multirow{2}{*}{ HR $1.87 ; 95 \%$ CI: $0.88-3.98 ; p=0.121$} \\
\hline LOH 19q (-) $(\mathrm{n}=29)$ & 12 months (range $3-48$ ) & \\
\hline LOH 9p $(+)(n=8)$ & 10.0 months (range $3-19$ ) & \multirow{2}{*}{ HR $1.62 ; 95 \%$ CI: $0.72-3.66 ; p=0.261$} \\
\hline LOH 9p $(-)(n=28)$ & 11.5 months (range $2-48$ ) & \\
\hline LOH 10q $(+)(n=14)$ & 11.5 months (range $3-19$ ) & \multirow{2}{*}{ HR $1.43 ; 95 \%$ CI: $0.71-2.89 ; \mathrm{p}=0.318$} \\
\hline LOH 10q $(-)(n=25)$ & 11 months (range 2-48) & \\
\hline LOH 13q $(+)(n=4)$ & 12.5 months (range $2-20$ ) & \multirow{2}{*}{ HR 0.9; 95\% CI: $0.33-2.71 ; p=0.924$} \\
\hline LOH 13q (-) $(n=34)$ & 11 months (range $2-48$ ) & \\
\hline LOH 17p $(+)(n=5)$ & 11.0 months (range $3-18$ ) & \multirow{2}{*}{ HR 1.36; 95\% CI: $0.51-3.58 ; p=0.549$} \\
\hline LOH $17 p(-)(n=30)$ & 12 months (range 2-48) & \\
\hline LOH 1p/19q $(+)(n=3)$ & 12 months (range 5-17) & \multirow{2}{*}{ HR $1.17 ; 95 \%$ CI: $0.36-3,8 ; p=0.79$} \\
\hline LOH $1 \mathrm{p} / 19 \mathrm{q}(-)(\mathrm{n}=32)$ & 11 months (range 2-48) & \\
\hline Any LOH $(+)(n=26)$ & 11 months (range 2-19) & \multirow{2}{*}{ HR 3.07; 95\% CI: $1.29-7.3 ; \mathrm{p}=0.006$} \\
\hline Any LOH $(-)(n=14)$ & 13.0 months (range 6-48) & \\
\hline
\end{tabular}

$13 q$ and $17 p$ has been reported previously, but their prognostic influence in glioblastoma is still controversial [14, 18, 20-22, 29]. In this study $\mathrm{LOH}$ in at least one of the loci in all examined chromosomes was detected in $65 \%$ of cases. The presence of $\mathrm{LOH}$ at any of the loci examined (except LOH 13q) was related to a significant unfavorable impact on the overall survival of the patients (hazard ratio 3.07; 95\% CI: 1.29-7.31; $\mathrm{p}=0.006$ ) (Table III). In contrast, in a large GB study no correlation was found with survival for LOH 1p, 19q, LOH 9p or LOH 10q or other molecular alterations (EGFR amplification, CDK4 amplification, INK4A/ARF deletion) analyzed either alone or by groups of alterations [19]. We did not find any prognostic significance of $\mathrm{LOH}$ as a single parameter (Table III).

A shorter median survival in patients with $\mathrm{LOH} \mathrm{10q}$ had been reported previously [1] especially at the PTEN locus [22]. On the other hand, Houillier et al. found no correlation between LOH 10q and survival [19], which was consistent with our study.

In our study the frequency of LOH10q was $38.5 \%$. This frequency has been reported in approximately 36$76 \%$ of GB cases depending on the microsatellite markers used $[1,19,22]$. The 10q25, 10q23-24, 10p14-p15 and $10 \mathrm{q} 23$ regions were reported as most frequently deleted on chromosome 10 [1, 22]. The loci of several tumor suppressor genes have been identified on chromosome 10, i.e. PTEN/MMAC1 on 10q23.3 (satellite marker D10S1765) and suppressor gene DMBT1 (10q25.3-q26) [30, 31]. PTEN is a regulator of cell cycle, progression and apoptosis via the PI3K-AKT pathway, and is frequently lost in $\mathrm{GB}$, mainly involved in late sequences of genetic alteration [32]. The LOH of

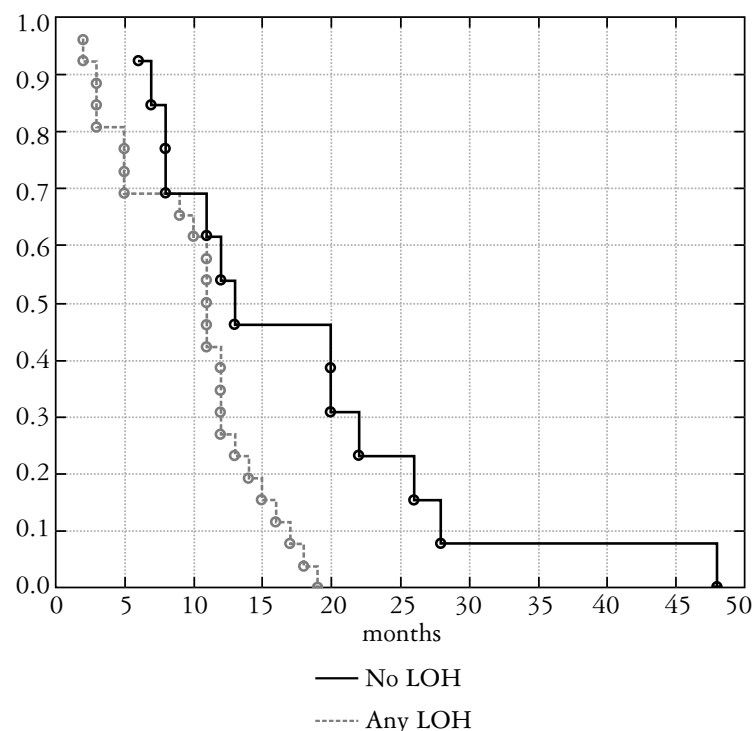

Fig. 2. Kaplan-Meier estimates for overall survival in all patients based on $\mathrm{LOH}$ status. Median overall survival of any $\mathrm{LOH}(+)$ patients was 11 months (range from 2-19 months), while median survival time in the $\mathrm{LOH}(-)$ group was 13.0 months (range from 6-48 months) $(p=0.007)$

the DMBT1 gene locus occurs in $21 \%$ to $79 \%$ of $\mathrm{GB}$ cases $[22,23]$. Homozygous deletion of the DMBT1 gene was detected at a similar frequency (about 20\%) in primary glioblastomas and secondary glioblastomas, suggesting that loss of DMBT1 is involved in the pathogenesis of both subtypes of glioblastoma and was significantly associated with shorter overall survival [33]. 
In this study, LOH 9p (locus on chromosome 9p21$22)$ was detected in $22.2 \%$ of cases. The CDKN $2 A$ (INK4A/ARF) genetic locus on chromosome 9p21 encodes two tumor suppressors: the $p 16 I N K 4 A$ cell cycle suppressor and $p 14 A R F[34,35]$, a regulator of TP53 stability. $\mathrm{LOH} 17 \mathrm{p}$ was detected in $14.3 \%$ and like TP53 mutation it has no impact on prognosis. In a previous study, poorer survival was associated significantly with the occurrence of either deletion of p16 $(\mathrm{p}=0.031), \mathrm{LOH}$ on $9 \mathrm{p}(\mathrm{p}=0.016)$, or $\mathrm{LOH}$ on $10 \mathrm{q}$ $(\mathrm{p}=0.0007)$ in high-grade gliomas, but LOH $17 \mathrm{p}$ and TP53 mutation had no statistically significant effect on survival after adjustment for age [36].

Loss of heterozygosity at $13 \mathrm{q}$, which includes the $R B 1$ gene, has been detected in $12 \%$ of primary glioblastomas [37], which is similar to our results (10\%). LOH 13q was excluded from the analysis because it was associated with a hazard ratio (HR) below 1.00 , while all other LOHs were associated with $\mathrm{HR}>1.00$. We have not found in the literature data about the influence of $\mathrm{LOH} \mathrm{13q}$ on patient survival in GB.

In the present study, the frequencies of $\mathrm{LOH} 1 \mathrm{p}, \mathrm{LOH}$ $19 \mathrm{q}$ and co-deletion of $\mathrm{LOH} 1 \mathrm{p} / 19 \mathrm{q}$ were $17.9 \%, 25.6 \%$ and $7.14 \%$, respectively. These results are consistent with other studies; the ranges of frequency of $\mathrm{LOH} 1 \mathrm{p}, 19 \mathrm{q}$ and $\mathrm{LOH} 1 \mathrm{p} / 19 \mathrm{q}$ co-deletion were as follows: $0-24 \%$, $5.3-33 \%$ and $0-13.3 \%$, respectively $[12,18]$.

Although the co-deletion LOH $1 \mathrm{p} / 19 \mathrm{q}$ is an important diagnostic and prognostic marker of chemosensitivity in oligodendrogliomas [5], its occurrence is not frequent in primary GB $[12,14,18]$ and is mainly associated with the oligodendroglial component (GB-O). The frequency of GB-O in the whole group of glioblastomas has been observed in the range from $4.2 \%$ up to $27.2 \%[17,21,29,38]$. In GB-O cases, the frequency of $\mathrm{LOH} 1 \mathrm{p}$ was from 12 to $24 \%, 19 \mathrm{q}$ was from 32 to $43 \%$, and combined $1 \mathrm{p} / 19 \mathrm{q}$ was from 22 to $28 \%$ $[39,40]$. In the more recent EORTC/NCIC trial study concerning a large group of $360 \mathrm{~GB}$ cases, an oligodendroglial component was found in $15 \%$ of all cases but co-deletion of $1 \mathrm{p} / 19 \mathrm{q}$ was found in only one case [41]. Intriguingly, a more detailed study in GB-O using microdissection of tumor tissues with astrocytic and oligodendroglial components revealed no difference in the pattern of genetic alterations on chromosomes $1 \mathrm{p}$ and $19 q$ in the same tumors [21]. In our study $\mathrm{LOH}$ $1 \mathrm{p} / 19 \mathrm{q}$ co-deletion was infrequent and there was no co-presentation with IDH1 mutation, which is consistent with the histopathological lack of oligodendroglial component in these cases. Although the occurrence of $1 \mathrm{p} / 19 \mathrm{q}$ loss has been associated with better prognosis in glioblastoma $[4,18]$, another study showed no impact on the prognosis of GB, even within the oligodendroglial component (GB-O) [21]. In our study there was no influence of $\mathrm{LOH} 1 \mathrm{p} / 19 \mathrm{q}$ co-deletion on overall patient survival.

\section{Conclusions}

Although the present study did not show any prognostic significance of $\mathrm{LOH}$ as a single parameter, the presence of $\mathrm{LOH}$ in at least one of the loci on all examined chromosomes (except LOH 13q) was related to a significant unfavorable impact on the overall survival of the patients.

We concluded that in primary glioblastoma a specific LOH group analysis may be important for the prognosis. In contrast to oligodendroglioma and secondary glioblastoma, $1 \mathrm{p} / 19 \mathrm{q}$ co-deletion is rare in glioblastoma without an oligodendroglial component and does not influence glioblastoma patients' survival.

The authors declare no conflicts of interest.

The study was supported by funding from the Minister of Science and Higher Education grant no. 2011/01/B/NZ4/03345, and by the funds of the Medical University of Lodz no. 503/ 1-034-03/503-01. We thank Dr Waldemar Och (Department of Neurosurgery, Regional Specialist Hospital, Olsztyn) for the delivery of tumor samples.

\section{References}

1. Ohgaki H, Dessen P, Jourde B, et al. Genetic pathways to glioblastoma: a population-based study. Cancer Res 2004; 64: 6892-6899.

2. Ohgaki H, Kleihues P. Population-based studies on incidence, survival rates, and genetic alterations in astrocytic and oligodendroglial gliomas. J Neuropathol Exp Neurol 2005; 64: 479489.

3. Yan H, Parsons DW, Jin G, et al. IDH1 and IDH2 mutations in gliomas. N Engl J Med 2009; 360: 765-773.

4. Hill C, Hunter SB, Brat DJ. Genetic markers in glioblastoma: prognostic significance and future therapeutic implications. Adv Anat Pathol 2003; 10: 212-217.

5. Aldape K, Burger PC, Perry A. Clinicopathologic aspects of $1 \mathrm{p} / 19 \mathrm{q}$ loss and the diagnosis of oligodendroglioma. Arch Pathol Lab Med 2007; 131: 242-251.

6. Stupp R, Hegi ME, Mason WP, et al. Effects of radiotherapy with concomitant and adjuvant temozolomide versus radiotherapy alone on survival in glioblastoma in a randomized phase III study: 5-year analysis of the EORTC-NCIC trial. Lancet Oncol 2009; 10: 459-466.

7. Boots-Sprenger SH, Sijben A, Rijntjes J, et al. Significance of complete 1p/19q co-deletion, IDH1 mutation and MGMT promoter methylation in gliomas: use with caution. Mod Pathol 2013; 26: 922-929.

8. Jesien-Lewandowicz E, Jesionek-Kupnicka D, Zawlik I, et al. High incidence of MGMT promoter methylation in primary glioblastomas without correlation with TP53 gene mutations. Cancer Genet Cytogenet 2009; 188: 77-82.

9. Adamek D, Zazula M, Radwańska E, et al. Co-occurrence of MGMT gene promoter methylation and amplification of EGFR in glioblastoma. Contemp Oncol (Pozn) 2011; 15: 362-366.

10. Birner P, Toumangelova-Uzeir K, Natchev S, Guentchev M. Expression of mutated isocitrate dehydrogenase- 1 in gliomas is associated with p 53 and EGFR expression. Folia Neuropathol 2011; 49: 88-93. 
11. Labussière M, Idbaih A, Wang XW, et al. All the 1p19q codeleted gliomas are mutated on IDH1 or IDH2. Neurology 2010; 74: 1886-1890.

12. Ueki K, Nishikawa R, Nakazato Y, et al. Correlation of histology and molecular genetic analysis of 1p, 19q, 10q, TP53, EGFR CDK4, and CDKN2A in 91 astrocytic and oligodendroglial tumors. Clin Cancer Res 2002; 8: 196-201.

13. Shinojima N, Tada K, Shiraishi S, et al. Prognostic value of epidermal growth factor receptor in patients with glioblastoma multiforme. Cancer Res 2003; 63: 6962-6970.

14. Kaneshiro D, Kobayashi T, Chao ST, et al. Chromosome 1p and $19 q$ deletions in glioblastoma multiforme. Appl Immunohistochem Mol Morphol 2009; 17: 512-516.

15. Nakamura M, Yang F, Fujisawa H, et al. Loss of heterozygosity on chromosome 19 in secondary glioblastomas. J Neuropathol Exp Neurol 2000; 59: 539-554.

16. Ino Y, Zlatescu MC, Sasaki $\mathrm{H}$, et al. Long survival and therapeutic responses in patients with histologically disparate highgrade gliomas demonstrating chromosome 1p loss. J Neurosurg 2000; 92: 983-990.

17. Homma T, Fukushima T, Vaccarella S, et al. Correlation among pathology, genotype, and patient outcomes in glioblastoma. J Neuropathol Exp Neurol 2006; 65: 846-854.

18. Schmidt MC, Antweiler S, Urban N, et al. Impact of genotype and morphology on the prognosis of glioblastoma. J Neuropathol Exp Neurol 2002; 61: 321-328.

19. Houillier C, Lejeune J, Benouaich-Amiel A, et al. Prognostic impact of molecular markers in a series of 220 primary glioblastomas. Cancer 2006; 106: 2218-2223.

20. Weller M, Felsberg J, Hartmann C, et al. Molecular predictors of progression-free and overall survival in patients with newly diagnosed glioblastoma: a prospective translational study of the German Glioma Network. J Clin Oncol 2009; 27: 5743-5750.

21. Pinto LW, Araújo MB, Vettore AL, et al. Glioblastomas: correlation between oligodendroglial components, genetic abnormalities, and prognosis. Virchows Arch 2008; 452: 481-490.

22. Tada K, Shiraishi S, Kamiryo T, et al. Analysis of loss of heterozygosity on chromosome 10 in patients with malignant astrocytic tumors: correlation with patient age and survival. J Neurosurg 2001; 95: 651-659.

23. Fujisawa $H$, Reis RM, Nakamura M, et al. Loss of heterozygosity on chromosome 10 is more extensive in primary (de novo) than in secondary glioblastomas. Lab Invest 2000; 80: 65-72.

24. Kleihus P, Burger PC, Aldape KD, et al. Glioblastoma. In: WHO classification of tumours of the central nervous system. Louis DN, Khaki H, Wiestler OD, Cavenee WK (eds.). IARC Press, Lyon, France 2007; 33-49.

25. Watanabe K, Sato K, Biernat W, et al. Incidence and timing of $\mathrm{p} 53$ mutations during astrocytoma progression in patients with multiple biopsies. Clin Cancer Res 1997; 3: 523-530.

26. Karsy M, Gelbman M, Shah P, et al. Established and emerging variants of glioblastoma multiforme: review of morphological and molecular features. Folia Neuropathol 2012; 50: 301-321.

27. Ohgaki H, Kleihues P. The definition of primary and secondary glioblastoma. Clin Cancer Res 2013; 19: 764-772.

28. Rieske P, Golanska E, Zakrzewska M, et al. Arrested neural and advanced mesenchymal differentiation of glioblastoma cells-comparative study with neural progenitors. BMC Cancer 2009; 9: 54.

29. Salvati M, Formichella AI, D’Elia A, et al. Cerebral glioblastoma with oligodendrogliomal component: analysis of 36 cases. J Neurooncol 2009; 94: 129-134.

30. Mollenhauer J, Wiemann S, Scheurlen W, et al. DMBT1, a new member of the SRCR superfamily, on chromosome 10q25. $3-26.1$ is deleted in malignant brain tumours. Nat Genet 1997; 17: 32-39.

31. Li J, Yen C, Liaw D, et al. PTEN, a putative protein tyrosine phosphatase gene mutated in human brain, breast, and prostate cancer. Science 1997; 275: 1943-1947.
32. Knobbe CB, Merlo A, Reifenberger G. PTEN signaling in gliomas. Neuro Oncol 2002; 4: 196-211.

33. Motomura K, Mittelbronn M, Paulus W, et al. DMBT1 homozygous deletion in diffuse astrocytomas is associated with unfavorable clinical outcome. J Neuropathol Exp Neurol 2012; 71: 702-707

34. Quelle DE, Zindy F, Ashmun RA, Sherr CJ. Alternative reading frames of the INK4a tumor suppressor gene encode two unrelated proteins capable of inducing cell cycle arrest. Cell 1995; 83: 993-1000.

35. Sharpless NE. INK4a/ARF: a multifunctional tumor suppressor locus. Mutat Res 2005; 576: 22-38.

36. Rasheed A, Herndon JE, Stenzel TT, et al. Molecular markers of prognosis in astrocytic tumors. Cancer 2002; 94: 2688-2697.

37. Nakamura M, Yonekawa Y, Kleihues P, Ohgaki H. Promoter hypermethylation of the RB1 gene in glioblastomas. Lab Invest $2001 ; 81: 77-82$.

38. Vordermark D, Ruprecht K, Rieckmann P, et al. Glioblastoma multiforme with oligodendroglial component (GBMO): favorable outcome after post-operative radiotherapy and chemotherapy with nimustine (ACNU) and teniposide (VM26). BMC Cancer 2006; 6: 247 .

39. He J, Mokhtari K, Sanson M, et al. Glioblastomas with an oligodendroglial component: a pathological and molecular study. J Neuropathol Exp Neurol 2001; 60: 863-871.

40. Miller CR, Perry A. Glioblastoma. Arch Pathol Lab Med 2007; 131: 397-406.

41. Hegi ME, Janzer RC, Lambiv WL, et al.; European Organisation for Research and Treatment of Cancer Brain Tumour and Radiation Oncology Groups; National Cancer Institute of Canada Clinical Trials Group. Presence of an oligodendroglioma-like component in newly diagnosed glioblastoma identifies a pathogenetically heterogeneous subgroup and lacks prognostic value: central pathology review of the EORTC_26981/NCIC_CE.3 trial. Acta Neuropathol 2012; 123: 841-852.

\section{Address for correspondence}

\section{Dorota Jesionek-Kupnicka, $\mathrm{PhD}$}

Department of Pathology, Chair of Oncology

Medical University of Lodz

Pomorska 251

92-213 Lodz, Poland

fax +48422725604

e-mail: dorota.jesionek-kupnicka@umed.lodz.pl 